\title{
Nondestructive evaluation techniques for thick concrete (Erratum)
}

\section{Dwight Clayton, Austin Albright, Alan Barker, Hector Santos-Villalobos}

Dwight A. Clayton, Austin Albright, Alan Barker, Hector Santos-Villalobos, "Nondestructive evaluation techniques for thick concrete (Erratum)," Proc. SPIE 10169, Nondestructive Characterization and Monitoring of Advanced Materials, Aerospace, and Civil Infrastructure 2017, 1016931 (9 January 2020); doi: 10.1117/12.2566164 Health Monitoring, 2017, Portland, Oregon, United States 


\section{Nondestructive evaluation techniques for thick concrete (Erratum)}

Dwight A. Clayton (retired), Austin Albright, Alan Barker, Hector Santos-Villalobos

Oak Ridge National Lab. (United States)

Proceedings Volume 10169, Nondestructive Characterization and Monitoring of Advanced Materials, Aerospace, and Civil Infrastructure 2017; 101690N (2017)

https://doi.org/10.1117/12.2258327

Event: Nondestructive Characterization and Monitoring of Advanced Materials, Aerospace, Civil Infrastructure, and Transportation XI, 2017, Portland, United States

Online Publication Date: 19 April 2017

Erratum Published: 9 January 2020

A revised version of this manuscript, which includes additional authors, was published on 9 January 2020. The original paper has been updated. 